duje.dicle.edu.tr

Araştırma Makalesi/ Research Article

\title{
EEG Verilerine Uygulanan Senkrosıkıştırma Yönteminin Migren Teşhisinde Kullanılmas1
}

\section{The Use of Synchrosqueezing Method Applied to EEG Data in the Diagnosis of Migraine \\ İbrahim DURSUN ${ }^{1 *}$, Mehmet AKIN ${ }^{2}$}

${ }^{1}$ Dicle Üniversitesi, Elektrik Elektronik Mühendisliği Bölümü, Diyarbakır, ibrahimdursun02@gmail.com, ORCID: 0000-0003-4689-1972

${ }^{2}$ Dicle Üniversitesi, Elektrik Elektronik Mühendisliği Bölümü, Diyarbakır, makin @ dicle.edu.tr, ORCID: 0000-0001-5439-4824

\begin{tabular}{|c|c|}
\hline MAKALE BİLGİLERİ & ÖZ \\
\hline Makale Geçmişi: & $\begin{array}{l}\text { Migren, beyindeki sinir ve kan damarlarında meydana gelen değişimler sonucunda ortaya çıkan şiddetli } \\
\text { bir bas ağrısı hastalığıdır. Migren hastalığının biyomedikal cihazlarla teshisine dair bir yöntem henüz }\end{array}$ \\
\hline Geliș 1 Aralık 2021 & geliştirilmemiştir ancak literatürü incelediğimizde EEG sinyalleri kullanılarak migren hastalığının teşhisi \\
\hline Revizyon 20 Aralık 2021 & ile ilgili birçok çalışmanın yapıldığını görmekteyiz. \\
\hline Kabul 27 Aralık 2021 & \\
\hline Online 31 Aralık 2021 & $\begin{array}{l}\text { Bu çalışmada } 18 \text { migren hastası ve } 21 \text { kontrol grubundan oluşan } 39 \text { katılımcının EEG verileri kullanılmış } \\
\text { olup, alınan EEG kayıtlarının Senkrosıkıştırma Dönüşümü (SSD) ile zaman-frekans bilgileri elde }\end{array}$ \\
\hline \multirow[t]{2}{*}{$\begin{array}{l}\text { Anahtar Kelimeler: Migren, KNN, } \\
\text { DVM, Senkrosıkıştırma Dönüşümü, } \\
\text { EEG }\end{array}$} & $\begin{array}{l}\text { edilmiştir. Litreartür incelendiğinde beynin belirli bölge ve kanallarında migren hastalığının etkili olduğu } \\
\text { görülmüş ve beynin bu bölgelerine (F1, P7, P5, T7, C5, TP7, CP5, FP1, Fz, Cz, T8, C6) kanallarının } \\
\text { denk geldiği gözlemlenmiştir. }\end{array}$ \\
\hline & $\begin{array}{l}\text { SSD, seçili kanallar ve tüm kanallara uygulandıktan sonra oluşan veri kümelerine; medyan, ortalama, } \\
\text { standart sapma, basıklık, entropi ve çarpıklık işlemleri uygulanarak özellik vektörü elde edilmiştir. } \\
\text { Özellik vektörü elde edilen veriler \% } \% 25 \text { test ve } \% 75 \text { eğitim verisi olacak şekilde Destek Vektör } \\
\text { Makinaları (DVM), K En Yakın Komşu (KNN), Naive Bayes (NB) ve Karar Ağaçları (KA) } \\
\text { sınıflandırma yöntemlerine uygulanıp sonuçlar karşlaştırılmıştır. }\end{array}$ \\
\hline
\end{tabular}

\begin{tabular}{ll}
\hline ARTICLE INFO & ABSTRACT \\
\hline
\end{tabular}

\section{Article history:}

Received 1 December 2021 Received in revised form 20 December 2021

Accepted 27 December 2021 Available online 31 December 2021 Keywords: Migraine, KNN, DVM, Synchrosqueezing Transform, EEG

Doi:10.24012/dumf.1051421

* Sorumlu Yazar
Migraine is a severe headache disease that occurs as a result of changes in the nerves and blood vessels in the brain. A method for the diagnosis of migraine disease with biomedical devices has not been developed yet, but when we examine the literature, we see that many studies have been carried out on the diagnosis of migraine disease using EEG signals.

In this study, EEG data of 39 participants, consisting of 18 migraine patients and 21 control groups, were used, and time-frequency information was obtained by Synchrosqueezing Transformation (SST) of the EEG recordings. When the literature was examined, it was observed that migraine disease was effective in certain regions and channels of the brain, and it was observed that the channels of the brain (F1, P7, P5, T7, C5, TP7, CP5, FP1, Fz, Cz, T8, C6) correspond to these regions of the brain.

The obtained feature vector were applied to the Support Vector Machines (SVM), K Nearest Neighbor $(\mathrm{KNN})$, Naive Bayes (NB) and Decision Trees (KA) classification methods, as $25 \%$ test and $75 \%$ training data, and the results were compared. 


\section{Giris}

Migren, en yaygın baş ağrısı çeşitlerinden biri olup insan hayatını kısmen de olsa zorlaştıran bir beyin hastalığıdır. Migren hastalığını tetikleyen (aşırı ışığa maruz kalma, aç kalma, hava kirliliği ve hava değişimi, stres vb.) birçok etken bulunmaktadır. Kesin bir migren teşhisi yöntemi henüz yetkililer tarafindan kabul edilmemiş olmasına karşın, Uluslararası Baş Ağrısı Derneği (International Headache Society-IHS) kıstasları ile teşhis edilebilmektedir [1]. Literatürde otomatik migren teşhisi ile ilgili birçok çalışma bulunmaktadır[2,3,4]. Migren hastalığının teşhisinde birçok biyomedikal cihaz kullanılsa da; hem verilerin elde edinimindeki kolaylık, hem de ağrısız bir yöntem olmasından kaynaklı olarak Elektroensefalografi (EEG) daha çok tercih edilmektedir. EEG işaretleri geniş bir frekans aralığına sahip olmasına rağmen yaygın olarak $0.3-30 \mathrm{~Hz}$ aralı̆̆ındaki sinyaller incelenmektedir. Literatür incelendiğinde migren hastalığında delta $(0.3-4 \mathrm{~Hz})$ ve teta $(4-8 \mathrm{~Hz})$ bantlarının aktif olduğu gözlenmiş ve çalışmada bu bantlar kullanılmıştır[5,6,7]. Ayrıca beynin parietal, oksipital, temporal, frontal bölgeleri ve uluslararası 10-20 standardına göre T3-T5 kanallarında daha anlamlı veriler elde edildiği yapılan çalışmalarda görülmüş ve bu bölgeler karşılaştırıldığında yaklaşık olarak (F1, P7, P5, T7, C5, TP7, CP5, FP1, Fz, Cz, T8, C6) kanallarına denk geldiği belirlenmiş ve bu kanalların yerleşimi Şekil 1'de gösterilmiştir[2,8,9,10]. Delta ve teta bandı elde edilen EEG verilerine SSD ve (medyan, ortalama, standart sapma, basıklık, entropi ve çarpıklık) gibi istatistiksel işlemler uygulanarak özellik vektörü elde edilmiş ve DVM, KNN, NB ve KA siniflandırma algoritmaları ile sınıflandırma işlemi yapılmıştır. Çalışmanın akış şeması Şekil 2'de gösterilmiştir.

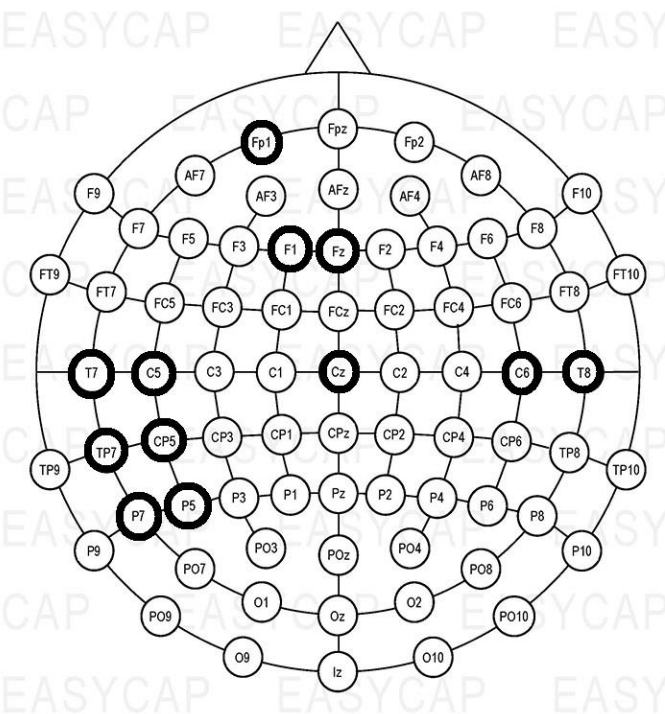

Şekil 1. Seçilen kanalların konumlarının gösterilmesi

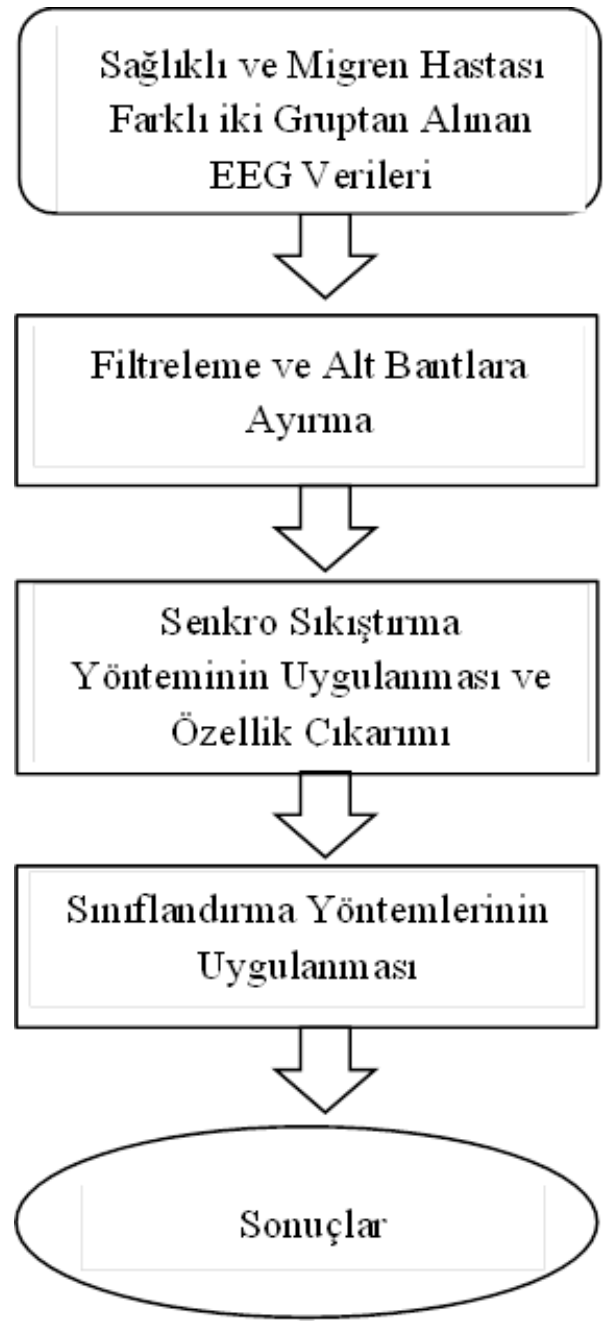

Şekil 2. Çalışmanın akışşeması

\section{Materyal ve Metot}

Veriler

$\mathrm{Bu}$ çalışmada kullanılan veriler Carnegie Mellon Üniversitesinden 18 yetişkin migren hastası (ortalama yaş 27.6; dağılım 19-54 yaş; 12 kadın ve 6 erkek ) ile 21, yaş ve cinsiyet uyumlu baş ağrısız kontrol (ortalama yaş 27.9; dağılım 19-54 yaş 12 kadın ve 9 erkek) grubundan alındı. Kontrol grubu yalnızca kendi bildirimlerine göre; baş ağrıları yoksa ve hiç baş ağrısı çekmemişse veya orta derecede ağrıdan daha az olan seyrek baş ağrıları varsa ve bu ağrılarla ortaya çıkan duyusal rahatsızlıkları yoksa dahil edilmiştir.

Migrenli gruptan 12 katılımc1 auralı migren ve 6 katılımcı aurasız migren olarak adlandırılan Uluslararası Baş Ağrısı Derneği'nin kriterlerini karşılamaktadır. Katılımcıların hiçbirine migren dışında nörolojik veya psikolojik teşhis konulmamış, önceden ciddi bir kafa travması veya sarsıntı geçirmemiştir. Katılımcıların işitme ve görme konusunda şikayetleri bulunmamakta ve bunlarla alakalı herhangi bir tedavi görmemişlerdir. Katılımcıların EEG kayıtları $512 \mathrm{~Hz}$ örnekleme frekansıyla 24 bitlik bir A/D dönüştürücü kullanılarak 
128 kanallı BioSemiActiveTwo sistemi ile hareketsiz halde alınmıştır[11]. Çalışmada kullanılan veriler katılımcılara herhangi bir uyartım verilmeden dinlenme durumunda alınan EEG kayıtlarıdır.

\section{Senkrosıkıştırma Dönüşümü}

Senkrosıkıştırma Dönüşümü (SSD), durağan olmayan sinyallerin yerelleşmiş zaman-frekans gösterimini oluşturmak için Sürekli Dalgacık Dönüşümüne uygulanan bir ileri işlem tekniğidir[12]. Sürekli dalgacık dönüşümü, dalgacık diye adlandırılan zaman-frekans filtrelerinin ilerlemesi ile söz konusu osilasyon bileşenlerini algılayan gösterim tabanlı bir yöntem iken, Senkrosıkıştırma dönüşümü, zamanla değişen osilasyonlara sahip bir sinyali bileşenlerine ayırmayı hedefler[13]. $x(t)$ bir sinyal olmak üzere SSD'nin genel formu aşağıdaki formül ile verilir.

$$
\mathrm{x}(\mathrm{t})=\sum_{k}^{K} x_{k}(t) e(t)
$$

Burada e(t) gürültüyü temsil etmekte, $x_{k} \quad(\mathrm{t})=$ $\left.A_{k}(\mathrm{t}) \cos \phi_{k}(\mathrm{t})\right)$ ise zamana göre genliği ve frekansı değişen bileşenleri göstermekte olup, genlik faktörü $A_{k}(\mathrm{t})$ ve anlık frekans olan $\phi_{k}(\mathrm{t})$ 'nin tüm $\mathrm{k}$ değerleri için bulunması gerekmektedir.

SSD üç adımda gerçekleşmektedir. İlk olarak x(t)'nin sürekli dalgacık dönüşümü $W_{x}(\mathrm{a}, \mathrm{b})$ hesaplanır.

$$
W_{x}(\mathrm{a}, \mathrm{b})=\int \alpha^{-\frac{1}{2}} \varphi\left(\frac{t-b}{\alpha}\right) x(t) d t
$$

İkinci aşamada $W_{x}(\mathrm{a}, \mathrm{b})$ kullanılarak anlık frekanslar $w_{x}(\mathrm{a}, \mathrm{b})$ bulunur.

$$
w_{x}(\mathrm{a}, \mathrm{b})=-i W(a, b)^{-1 \frac{\partial W(a, b)}{\partial b}}
$$

Üçüncü aşama ise Reassignment Method (Yeniden Atama Metodu) ile sıkıștırılması için kestirimin kullanıldığı aşamadır. Bu işlemler sonucundan sinyalin SSD'si $T_{x}(w, b)$ bulunur. SSD tersinir bir yöntem olup, $T_{x}$ biliniyorsa ' $\mathrm{x}$ ' bulunabilir [14].

$$
\begin{gathered}
T_{x}\left(w_{l}, b\right)=\sum a_{k}:\left|w_{x}\left(a_{k}, \mathrm{~b}\right)-w_{l}\right| \leq \\
\frac{\Delta w}{2} W\left(a_{k}, b\right) \alpha^{-3 / 2} \Delta a_{k}
\end{gathered}
$$

Çalışmada uygulanan SSD yönteminde Morlet dalgacık dönüşümü kullanılmıştır. Analitik bir dalgacık olan Morlet dalgacığı, jeofizikçi Jean Morlet'in Gabor dönüşümünü Grossman ile birlikte değiştirrerek kullanması sonucu ortaya çıkmıştır[15]. Morlet dalgacık fonksiyonu (5) denkleminde verilmiştir:

$$
m(x)=\pi^{1 / 4} \exp (\text { ic } x) \exp \left(-\frac{x^{2}}{2}\right)
$$

(5)'de c, sabit uzaysal frekanstır ve 5 ya da 6 alınır. Morlet dalgacığı ortogonal değildir, ölçeklendirme fonksiyonu yoktur.
Uluslararası 10-20 standardına göre yerleştirilmiş elektrotlardan C5 kanalından elde edilmiş migren hastası ve sağlıklı kişilere ait EEG kaydının SSD uygulanmış zaman-frekans grafiği Şekil 3-5'te ilk 10 ile 60 saniye ve tüm kayıt süresini kapsayan 382 saniyelik bölümleri gösterilmiştir.

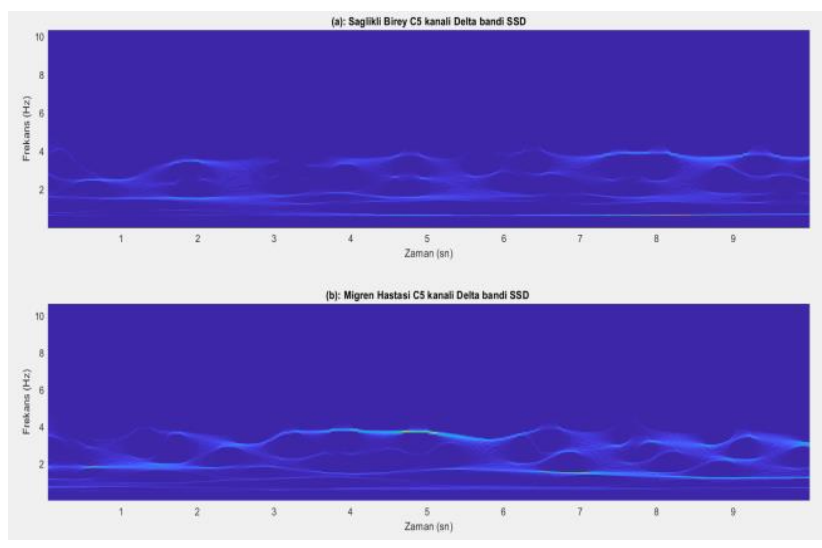

Şekil 3. (a) Sağlıklı ve (b) Migren hastasına ait 10 saniyelik EEG verilerinin SSD uygulanmış zamanfrekans grafiği

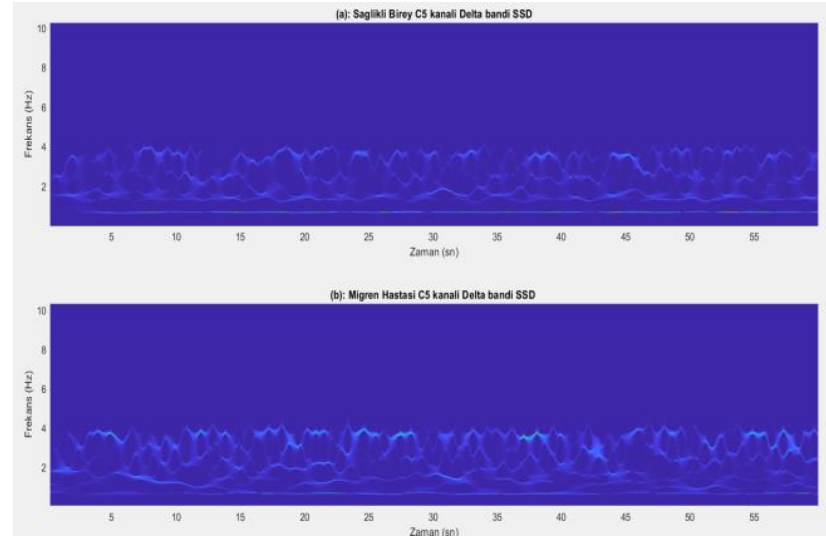

Şekil 4. (a) Sağlıklı ve (b) Migren hastasına ait 60 saniyelik EEG verilerinin SSD uygulanmış zamanfrekans grafiği

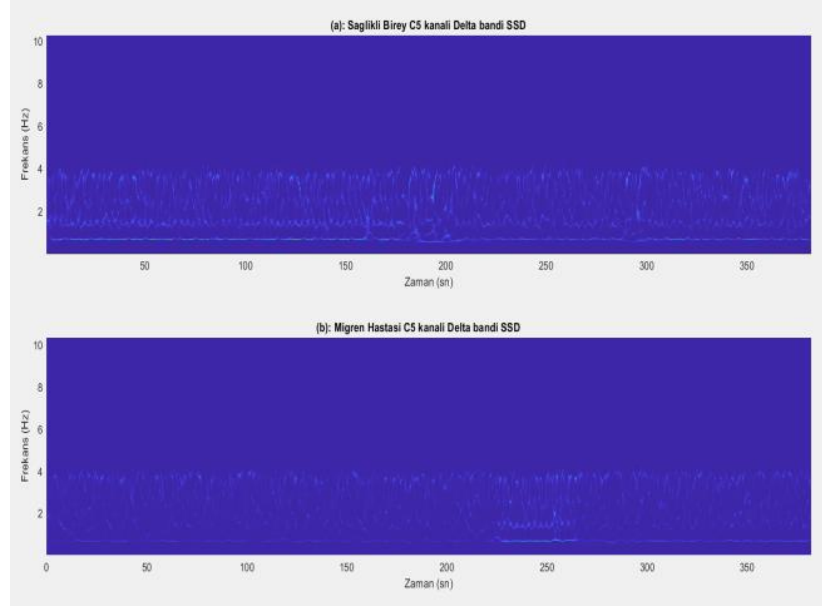

Şekil 5. (a) Sağlıklı ve (b) Migren hastasına ait 382 saniyelik EEG verilerinin SSD uygulanmış zamanfrekans grafiği 


\section{Destek Vektör Makinaları}

DVM, denetimli öğrenme yöntemi olup oldukça etkili ve basit bir algoritmadır. Temelde istatistiksel öğrenme teorisi ve yapısal risk minimizasyonuna dayanmaktadır.

DVM algoritmasında sınıflandırma işlemi nesnelerin -1 ve 1 olarak etiketlenmesine dayanır. DVM, sinıflandırma için bir düzlemde bulunan iki grup arasında bir sınır çizerek verileri iki gruba ayırmaya çalışır. Bu sınır çizgisi iki gruba en uzak mesafede olmalıdır. Şekil 6'da gösterildiği gibi pozitif ve negatif verileri birbirinden ayıran bir aşırı düzlem olsun. $\mathrm{Bu}$ düzlem üzerindeki noktalar $w \mathrm{x}+\mathrm{b}=0$ denklemini sağlayacaktır. Burada $\mathrm{w}$ aşırı düzleme olan normal ve $|b| /|| w||$ aşırı düzleme olan dik uzaklıktır. Aşırı düzleme en yakın pozitif ve negatif veriler arasındaki mesafeye ayırıcı aşırı düzlemin “tolerans"1 dersek, DVM bu toleransın en yüksek olduğu bir aşırı düzlemi bulmaya çalışır [16].

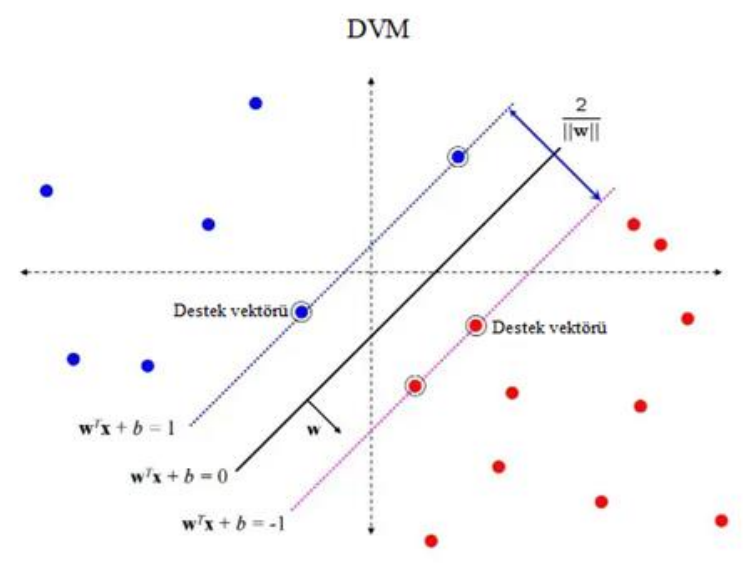

Şekil 6. DVM aşırı düzlemin belirlenmesi

$\mathrm{Bu}$ düzlemin bulunması için iki veri kümesine de yakın ve birbirine paralel iki sınır çizgisi çizilir. Bu iki sınır çizgisine paralel ve eşit mesafede ortak sınır çizgisi çizilerek veriler sınıflandırılır. Şekil 6'daki düzlemde her bir noktanın tanımı (6)'daki denklemle yapılabilir

$$
\mathrm{D}=\left\{\left(x_{i}, c_{i}\right) \mid\left(x_{i} \in \mathbb{R}^{\rho}, c_{i} \in\{-1,1\}\right\}_{i=1}^{n}\right.
$$

DVM algoritması kullanılırken rbf çekirdeği ve 1.0 trade off değeri seçilerek sınıflandırma işlemi yapılmıştır.

\section{K En Yakın Komşu Algoritması}

KNN algoritması, mevcut durumları saklayıp bir benzerlik ölçüsüne göre yeni durumları sınıflandıran basit bir algoritmadır. Algoritma temel olarak sınıflandırılacak verinin komşularıyla olan mesafesine bakıp en uygun etiket ile sınıflandırma işlemini yapmaktadır. Kendisine en yakın olan sınıfı belirlemek için bir k değişkeni kullanan algoritma sonuçları bu k değişkenine göre tahmin eder.

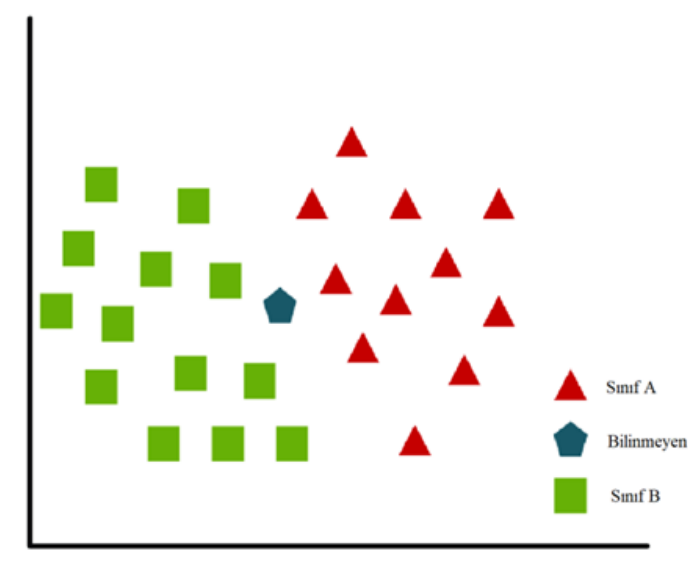

Şekil 7. KNN sınıflandırma algoritması

Şekil 7'de görüldüğü üzere KNN sinıflandırma algoritması, bilinmeyen veriyi belirlenmiş komşu sayısına göre kendisine en yakın verileri seçerek komşu sayısı yüksek çıkan sınıfa ait olduğuna karar verir. $\mathrm{k}$ komşu sayısı deneme yanılma yoluyla belirlenmekle beraber, eşit sayıda komşu sayısı çıkmasının önüne geçebilmek için tek sayı olması gerekmektedir. KNN sınıflandırma algoritmasında uzaklık hesaplamaları için genellikle 3 tip uzaklık fonksiyonu kullanılmaktadır. Bunlar;

- Euclidean Uzaklığı

- Manhattan Uzaklığ

- Minkowski Uzaklığı'dır.

$$
\begin{aligned}
& \text { Euclidean }=\sqrt{\sum_{i=1}^{k}\left(x_{i}-y_{i}\right)^{2}} \\
& \text { Manhattan }=\sum_{i=1}^{k}\left|x_{i}-y_{i}\right| \\
& \text { Minkowski }=\left(\sum_{i=1}^{k}\left(\left[x_{i}-y_{i}\right]\right)^{q}\right)^{1 / q}
\end{aligned}
$$

Uzaklık fonksiyonlarının matematiksel ifadeleri ise (7) (9) denklemlerinde verilmiştir. Çalışmada KNN algoritmasında komşuluk sayısı üç uzaklık fonksiyonu ise Minkowski kullanılmıştır.

\section{Naive Bayes}

Bayes teoremine dayanan NB sınıflandırma yöntemi mevcut sınıflanmış durumdaki örnek verileri kullanarak yeni bir verinin mevcut siniflardan herhangi birine ait olma olasılığını hesaplar. NB sinıflandırıcisında nitelikler birbirinden bağımsız, örnekler hepsi aynı derece öneme sahip ve bir özelliğin değeri başka bir özellik değeri hakkında bilgi içermez [17].

NB sınıflandırıcısının matematiksel gösterimi aşağıda gösterildiği gibidir:

$$
\mathrm{p}(y \mid X)=\frac{p(X \mid y) p(y)}{p(X)}
$$

Burada y şartlar belirtilmediğini gösteren sinıf değişkendir. $\mathrm{X}$ parametresi özellikleri temsil eder. $\mathrm{x}=$ $\left(x_{1}, x_{2}, x_{3}, \ldots, x_{n}\right)$ olsun $\mathrm{X}^{\prime} \mathrm{i}$ (10) denkleminde yerine yazarsak;

$\mathrm{p}\left(y \mid x_{1}, x_{2}, x_{3}, \ldots, x_{n}\right)=\frac{p\left(x_{1} \mid y\right) p\left(x_{2} \mid y\right) \ldots \ldots\left(x_{n} \mid y\right) p(y)}{p(x)}$ 
Veri kümesinde tüm girişler için payda değişmez bu yüzden payda çıkarılıp orantılılık uygulanabilir.

$$
\mathrm{p}\left(y \mid x_{1}, x_{2}, x_{3}, \ldots, x_{n}\right) \propto \mathrm{P}(\mathrm{y}) \prod_{i=1}^{n} P\left(x_{i} \mid y\right)
$$

Sınıf değişkeni y bu durumda sadece iki sonuca sahiptir. Sınıflandırıcının çok değişkenli olabileceği durumlarda y sınıfı maksimum olasılıkla bulunması gerekmektedir.

$$
\mathrm{Y}=\operatorname{argmax}_{y} P(y) \prod_{i=1}^{n} P\left(x_{i} \mid y\right)
$$

Yukarıdaki denklem kullanılarak verilen sınıfi elde edebiliriz. NB sınıflandırma çeşitleri, Multinomial, Bernoulli ve Gauss yöntemleri olup çalışmada NB Gauss yöntemi kullanılmıştır.

\section{Karar Ağaçları}

KA, kolay yorumu ve anlaşılabilirliği açısından sınıflandırma ve tahmin için sıklıkla kullanılan bir yöntemdir. KA tekniği sınıflama yaparken öğrenme ve sınıflandırma olmak üzere iki basamaklı işlem yapmaktadır. İlk basamak olan öğrenme basamağında önceden bilinen bir eğitim seti model oluşturmak için sinıflandırma algoritması tarafından analiz edilir. İkinci basamakta ise öğrenme basamağında oluşturan modelin daha önce görmediği test verileri kullanılarak KA'nın doğruluğu belirlenir. Eğer doğruluk kabul edilebilir oranda ise kurallar yeni verilerin siniflandırılması amaciyla kullanılır[18].

KA'da veri setindeki hangi alanların hangi sırada kullanılacağını belirlemede en yaygın olarak Entropi ölçümü kullanılmaktadır. Entropi değeri ne kadar büyük ise ortaya çıkan sonuçlar da o oranda belirsiz ve kararsız olur.

$$
\begin{array}{r}
E\left(C \mid A_{k}\right)=\sum_{j=1}^{M} p\left(a_{k}, j\right) x \\
\left\lceil-\sum_{i=1}^{N} p\left(c_{i} \mid a_{k}, j\right) \log _{2} p\left(c_{i} \mid a_{k}, j\right)\right\rceil
\end{array}
$$

(14) denkleminde;

$E\left(C \mid A_{k}\right)=A_{k}$ alanın sınıflandırma özelliğinin Entropi ölçüsü,

$\mathrm{p}\left(a_{k}, \mathrm{j}\right)=a_{k}$ alanının $\mathrm{j}$ değerinde olma olasılı $\breve{\mathrm{g}} 1$,

$\mathrm{p}\left(c_{i} \mid a_{k}, \mathrm{j}\right)=a_{k}$ alanı j. Değerindeyken sınıf değerinin $c_{i}$ olma olasılığ1,

$M_{k}=a_{k}$ alanının içerdiği değerlerin sayısı; $\mathrm{j}=1,2, \ldots, M_{k}$,

$\mathrm{N}=$ farklı sinıfların sayısı; $\mathrm{i}=1,2, \ldots, \mathrm{N}$,

$\mathrm{K}=$ alanların sayıs1; $\mathrm{k}=1,2, \ldots, \mathrm{K}$.

Eğer bir $\mathrm{S}$ kümesindeki elemanları kategorik olarak $C_{1}$, $C_{2}, C_{3}, \ldots C_{i}$ sınıflarına ayrıştırılırlarsa, $\mathrm{S}$ kümesindeki bir elemanın sınıfını belirlemek için gereken bilgi aşağıdaki formülle hesaplanmakatadır:

$\mathrm{I}(\mathrm{S})=-\left(p_{1} \log _{2}\left(p_{1}\right)+p_{2} \log _{2}\left(p_{2}\right)+\ldots+p_{i} \log _{2}\left(p_{i}\right)\right)($

Bu formülde $p_{i}, C_{i}$ sınıfına ayrılma olasılığıdır.

Entropi denklemi aşağıdaki şekilde de ifade edilebilir:

$$
\mathrm{E}(\mathrm{A})=\sum_{i=1}^{n} \frac{\left|S_{i}\right|}{|S|} x I\left(S_{i}\right)
$$

Bu durumda A alanı kullanılarak yapılacak dallanma işleminde, bilgi kazancı (17) formülüyle hesaplanmaktadir.

$$
\mathrm{G}(\mathrm{A})=\mathrm{I}(\mathrm{S})-\mathrm{E}(\mathrm{A})
$$

KA, bir düğümü alt düğümlere bölmeye karar vermek için birden fazla algoritma kullanır. Alt düğümler oluşturuldukça homojenliğide artar. Algoritma seçimi değişkenlerin tipine göre değişmekte olup en sik kullanılan algoritmalar; ID3, C4.5, C5.0 ve CART olarak sıralanabilir. $\mathrm{Bu}$ çalışmada KA sınıflandırıcısı kullanılırken ağaç oluşturma parametresi olarak Entropi seçilmiştir.

\section{ID3 Algoritması}

KA yapısını oluşturan birçok algoritmanın en iyilerinden biri olan ID3 (Iterative Dichotomiser 3) algoritmas1, Entropi'den faydalanarak sınıflandırma işlemini gerçekleştirir. Bu algoritma yinelemeli bir yapıya sahip olup sadece kategorik verilerle çalışmaktadır. ID3 algoritması 3 adımı esas alır: (C eğitim kümesi)

1. Adım: Eğer C'deki bütün kayıtlar aynı sınıf üyesi ise, sınıfın adında bir düğüm oluşturulur ve algoritma sonlanır, değilse bir test niteliği seçilerek karar düğümü oluşturulur.

2. Adım: $\mathrm{C}$ kümesi, karar düğümüne göre alt kümelere ayrilir: $C_{1}, C_{2}, C_{3}, \ldots C_{n}$

3. Adım: Algoritma her bir $C_{i}$ kümesine özyinelemeli bir şekilde uygulanır.

\section{C4.5 ve C5.0 Algoritmaları}

C4.5 algoritması KA algoritmalarından en yaygın olarak kullanılan ID3 algoritmasının geliştirilmiş halidir. C5.0 algoritması ise C4.5 algoritmasının geliştirilmiş hali olup, özellikle büyük veri setleri için kullanılmaktadır. Doğruluğu arttırmak için boosting algoritmasını kullandığından boosting ağaçları olarak da bilinmektedir. C5.0 algoritması C4.5 algoritmasına göre hafızayı daha verimli kullanarak daha hızlı sonuç vermektedir. Ayrıca C4.5 algoritmasına göre daha düzgün KA elde etmemizi sağlamaktadır.

\section{CART Algoritması}

Sinıflandırma ve regresyon problemlerinde bir çözüm olarak kullanılabilen CART algoritması hem sayısal hem de nominal veri türlerini, girdi ve kestirimsel değişken olarak alabilmektedir. Bu algoritmada KA, ikili olarak özyinelemeli biçimde bölünen bir yapıya sahiptir. Dallanma kriteri olarak Gini indeksini kullanıp sürekli bölünerek büyümektedir. Bölünmenin gerçekleşmeyeceği durumda, uçtan köke budama işlemi yapılır. Olası en başarılı KA, her budama işlemi sonrasında test verisi ile değerlendirilip tespit edilmeye çalışılır [19].

\section{Sonuçlar}

Çalışmada EEG verileri öncelikle migren hastalığının etkili olduğu bölgelere denk gelen (F1, P7, P5, T7, C5, TP7, CP5, FP1, Fz, Cz, T8, C6) kanallar ile tüm kanalları kapsayacak şekilde iki gruba ayrılmıştır ve bu 
gruplarda kendi içinde migren hastası ve sağlıklı olmak üzere iki gruba ayrılmıştır. Daha sonra bu veriler alt bantlara ayrıştırılarak delta ve teta bantları işlenmek üzere seçilmiştir. Seçilen alt bant verilerinin SSD dönüşümü ile zaman-frekans bilgisi elde edilmiş ve istatistiksel işlemler uygulanarak her iki grupta ayrı ayrı olmak üzere her bir birey için özellik vektörü elde edilmiştir. Elde edilen özellik vektörleri \%25 test ve $\% 75$ eğitim verisi olacak şekilde sınıflandırıcıların girişine uygulanmıştır. DVM, KNN, NB ve KA sınıflandırma algoritmaları aracılığıyla sınıflandırılan verilerin sonuçları Tablo 1-16'de gösterilmiştir.

Tablo 1. Seçili kanallar DVM sınıflandırma sonuç tablosu

\begin{tabular}{ccccc}
\hline $\begin{array}{c}\text { DVM } \\
\text { Sınıflandırıcısı }\end{array}$ & Kesinlik & Duyarlıık & $\begin{array}{c}\text { F1- } \\
\text { Skor }\end{array}$ & Dayanak \\
\hline Migren Hastası & 1 & 1 & 1 & 6 \\
Sağıklı & 1 & 1 & 1 & 4 \\
Doğruluk & & & 1 & 10 \\
Makro Ortalama & 1 & 1 & 1 & 10 \\
Ağırlıklı Ortalama & 1 & 1 & 1 & 10 \\
\hline
\end{tabular}

Tablo 2. Seçili kanallar DVM sınıflandırması hata matrisi

\begin{tabular}{|c|c|c|c|c|}
\cline { 3 - 5 } \multicolumn{2}{c|}{} & \multicolumn{2}{c|}{ Tahmin } & \multicolumn{1}{c}{} \\
\cline { 3 - 5 } \multicolumn{2}{c|}{ Geçek } & Hasta & Sağlıklı & Toplam \\
\cline { 2 - 5 } & Hasta & 6 & 0 & 6 \\
\cline { 2 - 5 } & Sağlıklı & 0 & 4 & 4 \\
\hline & Toplam & 6 & 4 & \multicolumn{2}{c}{}
\end{tabular}

Tablo 3. Seçili kanallar KNN sınıflandırma sonuç tablosu

\begin{tabular}{ccccc}
\hline $\begin{array}{c}\text { KNN } \\
\text { Sınıflandırıcısı }\end{array}$ & Kesinlik & Duyarlılık & $\begin{array}{c}\text { F1- } \\
\text { Skor }\end{array}$ & Dayanak \\
\hline Migren Hastası & 1 & 0.83 & 0.91 & 6 \\
Sağlıklı & 0.8 & 1 & 0.89 & 4 \\
Doğruluk & & & 0.90 & 10 \\
Makro Ortalama & 0.90 & 0.92 & 0.90 & 10 \\
Ağırlıklı Ortalama & 0.92 & 0.90 & 0.90 & 10 \\
\hline
\end{tabular}

Tablo 4. Seçili kanallar KNN sınıflandırması hata matrisi

\begin{tabular}{|c|c|c|c|c|}
\hline & \multicolumn{2}{|c|}{ Tahmin } & \multirow[b]{2}{*}{ Toplam } \\
\hline & & Hasta & Sağlıklı & \\
\hline \multirow{2}{*}{ Geçek } & Hasta & 5 & 1 & 6 \\
\hline & Sağlıklı & 0 & 4 & 4 \\
\hline & Toplam & 5 & 5 & \\
\hline
\end{tabular}

Tablo 5. Seçili kanallar NB sınıflandırma sonuç tablosu

\begin{tabular}{ccccc}
\hline $\begin{array}{c}\text { NB } \\
\text { Sınıflandırıcısı }\end{array}$ & Kesinlik & Duyarlılık & $\begin{array}{c}\text { F1- } \\
\text { Skor }\end{array}$ & Dayanak \\
\hline Migren Hastası & 1 & 0.83 & 0.91 & 6 \\
Sağlıklı & 0.8 & 1 & 0.89 & 4 \\
Doğruluk & & & 0.90 & 10 \\
Makro Ortalama & 0.90 & 0.92 & 0.90 & 10 \\
Ağırlıklı & 0.92 & 0.90 & 0.90 & 10 \\
Ortalama & & & \\
\hline
\end{tabular}

Tablo 6. Seçili kanallar NB sınıflandırması hata matrisi

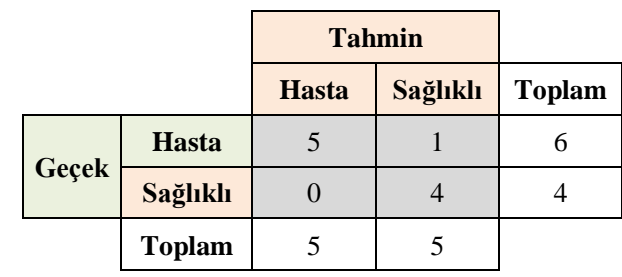

Tablo 7. Seçili kanallar KA sınıflandırma sonuç tablosu

\begin{tabular}{ccccc}
\hline $\begin{array}{c}\text { KA } \\
\text { Sınıflandırıcısı }\end{array}$ & Kesinlik & Duyarlılık & $\begin{array}{c}\text { F1- } \\
\text { Skor }\end{array}$ & Dayanak \\
\hline Migren Hastası & 1 & 0.83 & 0.91 & 6 \\
Sağlıklı & 0.8 & 1 & 0.89 & 4 \\
Doğruluk & & & 0.90 & 10 \\
Makro Ortalama & 0.90 & 0.92 & 0.90 & 10 \\
Ağırlıklı Ortalama & 0.92 & 0.90 & 0.90 & 10 \\
\hline
\end{tabular}

Tablo 8. Seçili kanallar KA sınıflandırması hata matrisi

\begin{tabular}{|c|c|c|c|c|}
\cline { 3 - 5 } \multicolumn{2}{c|}{} & \multicolumn{2}{c|}{ Tahmin } & \multicolumn{1}{c}{} \\
\cline { 2 - 5 } \multicolumn{2}{c|}{} & Hasta & Sağıklı & Toplam \\
\hline \multirow{3}{*}{ Geçek } & Hasta & 5 & 1 & 6 \\
\cline { 2 - 5 } & Sağlıklı & 0 & 4 & 4 \\
\hline & Toplam & 5 & 5 & \multicolumn{2}{c}{} \\
\cline { 2 - 4 } & & \multicolumn{2}{c}{}
\end{tabular}

Tablo 9. Tüm kanallar DVM sınıflandırma sonuç tablosu

\begin{tabular}{ccccc}
\hline $\begin{array}{c}\text { DVM } \\
\text { Sınıflandırıcısı }\end{array}$ & Kesinlik & Duyarlılık & $\begin{array}{c}\text { F1- } \\
\text { Skor }\end{array}$ & Dayanak \\
\hline Migren Hastası & 0.83 & 0.83 & 0.83 & 6 \\
Sağlıklı & 0.75 & 0.75 & 0.75 & 4 \\
Doğruluk & & & 0.80 & 10 \\
Makro Ortalama & 0.79 & 0.79 & 0.79 & 10 \\
Ağırlıklı Ortalama & 0.80 & 0.80 & 0.80 & 10 \\
\hline
\end{tabular}

Tablo 10. Tüm kanallar DVM sinıflandırması hata matrisi

\begin{tabular}{|c|c|c|c|c|}
\cline { 3 - 5 } \multicolumn{2}{c|}{} & \multicolumn{2}{c|}{ Tahmin } & \multicolumn{1}{c}{} \\
\cline { 3 - 5 } \multicolumn{2}{c|}{ Geçek } & Hasta & Sağlıkı & Toplam \\
\cline { 2 - 5 } & Hasta & 5 & 1 & 6 \\
\hline & Sağlıkıı & 1 & 3 & 4 \\
\hline & Toplam & 6 & 4 & \multicolumn{2}{c}{} \\
\cline { 2 - 4 } & &
\end{tabular}

Tablo 11. Tüm kanallar KNN sinıflandırma sonuç tablosu

\begin{tabular}{ccccc}
\hline $\begin{array}{c}\text { KNN } \\
\text { Sinıflandırıcısı }\end{array}$ & Kesinlik & Duyarııık & F1-Skor & Dayanak \\
\hline Migren Hastası & 0.80 & 0.67 & 0.73 & 6 \\
Sağlıklı & 0.60 & 0.75 & 0.67 & 4 \\
Doğruluk & & & 0.70 & 10 \\
Makro Ortalama & 0.70 & 0.71 & 0.70 & 10 \\
Ağırıklı Ortalama & 0.72 & 0.70 & 0.70 & 10 \\
\hline
\end{tabular}

Tablo 12. Tüm kanallar KNN sinıflandırması hata matrisi 


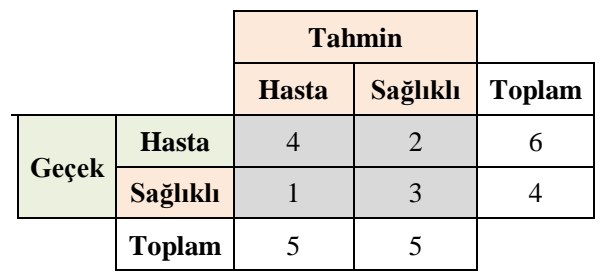

Tablo 13. Tüm kanallar NB sınıflandırma sonuç tablosu.

\begin{tabular}{ccccc}
\hline $\begin{array}{c}\text { NB } \\
\text { Sinıflandırıcısı }\end{array}$ & Kesinlik & Duyarlılık & $\begin{array}{c}\text { F1- } \\
\text { Skor }\end{array}$ & Dayanak \\
\hline Migren Hastası & 0.86 & 1 & 0.92 & 6 \\
Sağlıklı & 1 & 0.75 & 0.86 & 4 \\
Doğruluk & & & 0.90 & 10 \\
Makro Ortalama & 0.93 & 0.88 & 0.89 & 10 \\
Ağırlıklı Ortalama & 0.91 & 0.90 & 0.90 & 10 \\
\hline
\end{tabular}

Tablo 14. Tüm kanallar NB sınıflandırması hata matrisi

\begin{tabular}{|c|c|c|c|c|}
\hline & \multicolumn{2}{|c|}{ Tahmin } & \multirow[b]{2}{*}{ Toplam } \\
\hline & & Hasta & Sağlıklı & \\
\hline \multirow{3}{*}{ Geçek } & Hasta & 6 & 0 & 6 \\
\hline & Sağlıklı & 1 & 3 & 4 \\
\hline & Toplam & 7 & 3 & \\
\hline
\end{tabular}

Tablo 15. Tüm kanallar KA sınıflandırma sonuç tablosu.

\begin{tabular}{ccccc}
\hline $\begin{array}{c}\text { KA } \\
\text { Sinıflandırıcısı }\end{array}$ & Kesinlik & Duyarlılık & $\begin{array}{c}\text { F1- } \\
\text { Skor }\end{array}$ & Dayanak \\
\hline Migren Hastası & 1 & 0.83 & 0.91 & 6 \\
Sağılıkı & 0.8 & 1 & 0.89 & 4 \\
Doğruluk & & & 0.90 & 10 \\
Makro Ortalama & 0.90 & 0.92 & 0.90 & 10 \\
Ağırıklı Ortalama & 0.92 & 0.90 & 0.90 & 10 \\
\hline
\end{tabular}

Tablo 16. Tüm kanallar KA sınıflandırması hata matrisi

\begin{tabular}{|c|c|c|c|c|}
\hline & \multicolumn{2}{|c|}{ Tahmin } & \multirow[b]{2}{*}{ Toplam } \\
\hline & & Hasta & Sağlıklı & \\
\hline \multirow{3}{*}{ Geçek } & Hasta & 5 & 1 & 6 \\
\hline & Sağlıklı & 0 & 4 & 4 \\
\hline & Toplam & 5 & 5 & \\
\hline
\end{tabular}

Tablo 1-16 incelendiğinde DVM ve KNN sınıflandırma algoritmalarında tüm kanallardan alınan verilerin sinıflandırılmasından elde edilen sonuç ile seçili kanallardan alınan verilerin sinıflandırılmasından elde edilen sonuca kıyasla başarı oranı düşmektedir. NB sınıflandırıcısında ise sonuçların tümü düşüş göstermese de bazı parametrelerinde düşüş görülmekte olup KA sinıflandırıcısında ise herhangi bir değişiklik olmadığı görülmüştür. Genel olarak incelendiğinde ise DVM sınıflandırıcısının migren hastalığının etkili olduğu bölgelere denk gelen kanalların seçilmesiyle bu kanallara uygulanmasinın sonucunda siniflandırma başarısının en yüksek olduğu görülmüştür.

\section{Tartışma}

Bu çalışmada EEG verilerinin SSD yöntemiyle zamanfrekans bilgisi elde edilip migren hastalığı tespit edilmeye çalışılmıştır. Literatür incelendiğinde daha çok hastalara 4-6 $\mathrm{Hz}$ 1şı uyartımı verilerek EEG sinyallerinde oluşan değişiminden tespit edilmeye çalışıldığı görülmüştür. Ancak bu çalışmada dinlenme halindeki bireylerden alınan EEG kayitları ile sınıflandırma işlemi yapılmıştır. Ayrıca önceki çalışmalarda migren hastalarında beynin parietal, oksipital, temporal, ve frontal bölgelerinde hastalığın tespitinde anlamlı veriler elde edildiği belirtilmiş olsa da kanalların belirlenmesiyle ilgili çok çalışmaya rastlanmamıştır. $\mathrm{Bu}$ çalışmada etkin olan kanalları seçebilmek için ilgili bölgelere denk gelen kanallar belirlenip sınıflandırılmıştır. Ayrıca tüm kanallarında birlikte sınıflandırma işlemi yapılıp seçilen kanalların sonuçlarıyla karşılaştırılmıştır.

\section{Kaynaklar}

[1] S. Batuhan AKBEN, Ahmet ALKAN, "EEG Verilerine Uygulanan Deneysel Kip Ayrışımı Temelli Kümelemenin Migren Teşhisinde Kullanılması", ELECO '2012 Elektrik - Elektronik ve Bilgisayar Mühendisliği Sempozyumu, 29 Kasım - 01 Aralık 2012, Bursa.

[2] M. De Tommaso, D. Marinazzo, M. Guido, G. Libro, S. Stramaglia, L. Nitti, G. Lattanzi, L. Angelini, M. Pellicoro, Visually evoked phase synchronization changes of alpha rhythm in migraine: correlations with clinical features, Int. J. Psychophysiol. 57 (3) (2005) 203-210.

[3] Jensen, K., Tuxen, C., Olesen, J. 1988. Pericranial muscle tenderness and pressure-pain threshold in the temporal region during common migraine. Pain, 35 (1) : 65-70.

[4] Lia, C., Careninni, L., Degioz, C., and Bottachi, E. 1995. Computerized EEG analysis in migraine patients. Ital. J. Neurol. Sci., $16: 249-254$.

[5] Genco, S., De Tommaso, M., Prudenzano, A. M. P., Savarese, M., Puca, F. M. 1994. EEG features in juvenile migraine: topographic analysis of spontaneous and visual evoked brain electrical activity: a comparison with adult migraine. Cephalalgia, $14: 41-46$.

[6] Alberti, A., Mazzotta, M., Galletti, F. 2004. Electroencephalographic brain mapping and migraine. The Journal of Headache and Pain, 5:47-50.

[7] Bjork, M.H., Sand T. 2008. Quantitative EEG power and asymmetry increase $36 \mathrm{~h}$ before a migraine attack. Cephalagia, 28 (9) : 960-968.

[8] De Tommaso, M., Stramaglia, S., Schoffelen, J. M., Guido, M., Libro, G., Losito, L., Sciruicchio, V., Sardaro, M., Pellicoro, M. 2003. Steady-state visual evoked potentials in the low frequency range in migraine: a study of habituation and variability phenomena. Int. J. Psychophysiol., 49 : 165-174. 
[9] Drake, M.E., Du Bois, C., Stephen, B.A., Huber, J., Pakalnis, A., Denio, L. S. 2005. EEG Spectral Analysis and Time Domain Descriptors in Headache. 28 : 201 203.

[10] Mustafa Şeker, “Gebelik Sürecindeki Migrenli Hastalarda EEG Sinyallerinin İncelenmesi”,Yüksek Lisans Tezi, Kayseri, 2020.

[11] M. Chaman Zar, Alireza; Haigh, Sarah; Grover, Pulkit; Behrmann, "Ultra high- density EEG recording of interictal migraine and controls: sensory and rest. Carnegie Mellon University. Dataset.," 2020. https://doi.org/10.1184/R1/ 12636731.

[12]Ahrabian,A., Looney,D., Stanković,L., Mandic,D.P., (2015): "Synchrosqueezing-based time frequency analysis of multivariate data", Signal Processing, pp. 331-341, 2015.

[13] Özel, P., (2019): Çok Değişkenli Sinyal İşleme Teknikleri Kullanarak EEG İle Duygu Durum Analizi, Doktora, İstanbul Üniversitesi.

[14] Ozel, Pinar \& Akan, Aydin \& Yilmaz, Bulent. (2017). Emotion recognition classification in EEG signals using mu ltivariate synchrosqueezing transform.1-4.10.1109/TIPTEKNO.2017.823
[15] Yamamoto, A., \& T. L. Lee, D. (1994). Wavelet Analysis: Theory and Applications. HewlettPackard Journal, (December), 44-52. http://doi.org/10.1051/i p1:1997114

[16] Yasin KAYA, Hüseyin PEHLIVAN, "KNN, NN, BAYES, DT ve SVM Kullanılarak EKG Vurularının Sinıflandırılması", ISITES2014, Karabuk.

[17] Murat KARAKOYUN, Mehmet HACIBEYOĞLU, "Biyomedikal Veri Kümeleri İle Makine Öğrenmesi Sınıflandırma Algoritmalarının İstatistiksel Olarak Karşılaştırılması", DEÜ Mühendislik Fakültesi Mühendislik Bilimleri Dergisi, Cilt 16, Sayı 48, sh 3041,Eylül 2014.

[18]A., Çalış, S., Kayapınar, Ç., Çetinyokuş, "Veri Madenceliğinde Karar Ağacı Algoritmaları İle Bilgisayar ve İnternet Güvenliği Üzerine Bir Uygulama", Gazi Üniversitesi, Endüstri Mühendisliði DergisiCilt: 25 Sayý: 3-4 Sayfa: (2-19), 2014

[19] Sezer, E. A., Bozkır, A. S., Yağız, S., Gökçeoğlu C.2010. "Karar Ağacı Derinliğinin CART Algoritmasında Kestirim Kapasitesine Etkisi: Bir Tünel Açma Makinesinin İlerleme Hızı Üzerinde Uygulama," Akıllı Sistemlerde Yenilikler ve Uygulamaları Sempozyumu, Kayseri. 